\title{
Glioma and occupational exposure in Sweden, a case-control study
}

\author{
Ylva Rodvall, Anders Ahlbom, Bo Spännare, Gun Nise
}

\begin{abstract}
Objectives-The aim of the study was to analyse whether any job titles, industrial codes, and certain occupational exposures were associated with an increased risk of glioma.

Methods-A population based case-control study of incident primary brain tumours in adults was carried out in Uppsala, Sweden in the period 1987-90. The study included 192 cases of glioma and 192 matched controls. It also included cases with other tumours of the central nervous system with matched controls. Information from all 343 controls was used in this study. Information was collected by means of a questionnaire that was sent to all subjects. An occupational hygienist reviewed the questionnaires for self reported exposures to substances and assessed whether these reported exposures were plausible or not in the corresponding occupation.
\end{abstract}

Results-The $\kappa$ coefficient for those classified by the two methods ranged between 0.46 and 0.88 , and they were almost the same for cases and controls. For men exposed to solvents a relative risk (RR) of $2.6(95 \% \mathrm{CI} 1.3$ to $5 \cdot 2)$ was found. For men exposed to pesticides the RR was 1.8 (95\% CI 0.6 to $5 \cdot 1$ ), and for plastic materials the RR was $3.6(95 \%$ CI 1.0 to 12.4$)$. For men employed in forestry and logging the RR was $2.2(95 \% \mathrm{CI} 0.9$ to 5.3$)$ and in basic metal industries $2 \cdot 0(95 \%$ CI 1.0 to $4 \cdot 0)$.

Conclusion-An increased risk of glioma was associated with use of solvents, pesticides, and plastic materials but this should be interpreted with some caution.

Institute of

Environmental

Medicine, Karolinska

Institute, Stockholm,

Sweden

Y Rodvall

A Ahlbom

Department of

Neurosurgery, Uppsala

University Hospital,

Uppsala, Sweden

B Spännare

Department of

Occupational Health, Karolinska Hospital,

Stockholm, Sweden

G Nise

Correspondence to:

Ms Ylva Rodvall, Institute of

Environmental Medicine,

Box 210, S-17177

Stockholm, Sweden.

Accepted 26 February 1996
(Occup Environ Med 1996;53:526-537)

Keywords: glioma; case-control; occupational

Current understanding of the aetiology of brain tumours is limited. Brain tumours have been linked to a variety of environmental factors, ${ }^{1}$ but the only established risk factors among adults for glioma are genetic predisposition, which seems to account for only a small proportion of all cases, ${ }^{2}$ and ionising radiation. ${ }^{3}$ Occupations, such as the rubber industry, ${ }^{4-6}$ work exposed to vinyl chloride, ${ }^{7-9}$ farming, ${ }^{10}$ and work in electrical occupations with presumed exposure to magnetic fields, ${ }^{511-13}$ have been linked to an increased risk. Many of the occupations have exposure to organic solvents in common..$^{5614-17}$

An increasing incidence or mortality from brain tumours among elderly people is reported in many industrial countries but whether the increase is real or due to other circumstances, such as improved diagnostic criteria, is discussed. ${ }^{18-20}$

Increasing risk of brain tumour is found with increasing social class in some studies $^{421-22}$ and it is discussed whether this is an effect of occupation or if lifestyle factors are involved.

The present case-control study conducted in central Sweden is one of 10 case-control collaborative studies of adult brain tumours coordinated by the surveillance of environmental aspects related to cancer in humans (SEARCH) programme of the International Agency for Research on Cancer (IARC) in Lyon, France. The aim of this study was to analyse whether any job titles, industrial codes, and certain occupational exposures, are associated with an increased risk of glioma. The associations between social class, level and type of education, and gliomas were also investigated.

\section{Materials and methods}

The study population included all $25-74$ year old people who were registered as living in the catchment area of the Neurosurgery Department at Uppsala University Hospital, from March 1987 to February 1990. That covers about one million people in central Sweden.

\section{CASES}

We included all cases of newly diagnosed histologically confirmed intracranial gliomas, (international classification of diseases (ICD) code 191). ${ }^{23}$ Tumour grade was classified by the Kernohan system. ${ }^{24}$ Table I shows the diagnoses. Tumours found at necropsy were excluded. The tumours are sometimes difficult to classify as they are often mixed, with both astrocytes and oligocytes. For this reason and because of small numbers, all gliomas were analysed together regardless of subtype. However, analyses were also made with astrocytoma grade I and oligodendrogliomas excluded, but the results hardly changed. The case-control study also examined intracranial tumours other than gliomas and those results are presented elsewhere.

The information from Uppsala University Hospital was compared with information from the Regional Cancer Registry in Uppsala and 
this way we identified cases in the study population who were treated at hospitals other than the Uppsala University Hospital. We identified 192 cases of glioma in the study population during the observation period. Two pathologists at the Uppsala University Hospital classified all tumours, and histological typing was checked by one of the authors (BS).

\section{CONTROLS}

When we received information about a case, the parish office where the case was registered was contacted and we asked for a control with the same sex and, as close as possible, age. There are between 100 and 35000 inhabitants in each of the 450 parishes in the catchment area. Only controls alive at the time of diagnosis of the corresponding case were eligible. In the case-control study other diagnoses of the central nervous system such as meningioma and acoustic neurinoma were also included and 343 controls were selected in total. All these controls were used for the glioma analyses.

At the neurosurgery clinic a secretary asked the cases to participate. If the treating physician judged the case's condition to be too bad, or if the case died, a proxy was used. This was usually the spouse. Those who agreed received a questionnaire and a letter with information about the study. Cases already discharged from the hospital were contacted at home. A letter was sent to the controls with information about the study and that we intended to telephone one week later. A questionnaire was sent by post to those who agreed to participate.

One month after the questionnaire was posted a nurse attempted to telephone the cases if the questionnaire had not been returned or if it needed to be supplemented. The cases were sometimes difficult to reach because they were in local hospitals for rehabilitation or radiation treatment.

Of the 192 cases we managed to get information from 151 , from 128 in person $(79 \%)$, and from the proxies of 23 (table 1). Three per cent refused and $18 \%$ were dead or too sick to participate and were without an available proxy. After three reminders to the controls, there was a non-response of $18 \%$ (61 persons). Replacement controls were selected for all the 61 non-respondents. There was a lower response rate among elderly people both among cases and controls.

Specific questions about various exposures

Table 1 Response rate for subjects 25-74 years old by glioma type

\begin{tabular}{|c|c|c|c|c|c|}
\hline \multirow[b]{3}{*}{ Type of respondent } & \multirow{3}{*}{$\begin{array}{l}\text { Identified } \\
n\end{array}$} & \multirow{3}{*}{$\begin{array}{l}\text { Non-response } \\
n(\%)\end{array}$} & \multicolumn{3}{|l|}{ Response } \\
\hline & & & Total & Subject & Proxy \\
\hline & & & $n(\%)$ & $n(\%)$ & $n(\%)$ \\
\hline \multicolumn{6}{|l|}{ Glioma: } \\
\hline Astrocytoma I-II & 47 & $5(11)$ & $42(89)$ & $38(81)$ & $4(8)$ \\
\hline Astrocytoma III-IV & 123 & $34(28)$ & $89(72)$ & 73 (59) & $16(13)$ \\
\hline Oligodendroglioma & 20 & $2(10)$ & $18(90)$ & $16(80)$ & $2(10)$ \\
\hline $\begin{array}{l}\text { Non-specified } \\
\text { All }\end{array}$ & $\begin{array}{r}2 \\
192\end{array}$ & $41(21)$ & $\begin{array}{r}2(100) \\
151(79)\end{array}$ & $\begin{array}{r}1(50) \\
128(67)\end{array}$ & $\begin{array}{r}1(50) \\
23(12)\end{array}$ \\
\hline
\end{tabular}

were asked for each job held for more than three months. For each job, the type of industry was coded according to the international standard industrial classification of all economic activities (ISIC). ${ }^{25}$ The ISIC contains four digit levels where the first digit is the major group and the next digits are different levels of detail. Job titles were classified with five digits according to the international standard classification of occupations (ISCO). ${ }^{26} \mathrm{~A}$ card listing industrial chemicals and other exposures was included in the questionnaire. Subjects, someone working close to them, or other people out of the work area were asked if they had used these substances at work. Additional questions were also asked about how many hours a day, week, month, or year they came into contact with the substances. Several common specific exposures in each of the following categories were listed; pesticides and other agricultural chemicals, animal products, beauty products, dusts, insulation materials, metals, oils or coal products, paints, pigments and glues, plastic materials, radiation, solvents, degreasers, and high electrical currents.

An occupational hygienist (GN) reviewed the questionnaires for several specific self reported exposures and assessed whether they were probable in the corresponding occupation. The likelihood that an exposure had occurred in a reported occupation was assessed from 1 to 3 . Rank 1 was assigned to exposure present in less than $25 \%$ of the workers in the occupation, rank 2 was $25-74 \%$, and rank 3 was assigned to exposures present for at least $75 \%$. Further, the exposure level was estimated in four classes, 0 to 3 where 0 represented exposure to background level, about $1 / 30$ of the Swedish occupational exposure limit (OEL) ${ }^{27}$ An exposure ranging from 1/30 to $1 / 10$ of the OEL was given rank 1 , rank 2 was $1 / 10-1 / 3$, and rank 3 represented an exposure level of $>1 / 3$ of the OEL. The hygienist had information about company and job title and she also asked for more information for some of the people. All classification was blinded for case-control status. The self reported information was compared with the assessment of the occupational hygienist. The $\kappa$ coefficients and $95 \%$ confidence intervals (95\% CIs) were calculated. ${ }^{28}$

Social class was coded according to the Swedish socioeconomic classification in three different classes, which is based on job titles where $I$ is the highest class. ${ }^{29}$ Questions were asked about years of education divided into three categories, $<8$ years in school, 8-11 years, and $>11$ years. Specific questions were also asked about higher education.

Relative risks (RR) and 95\% CI were estimated with multiple logistic regression models with adjustment for the effects of potential confounding factors. ${ }^{30}$ The analyses were performed separately for men and women. As the controls were matched on sex, age, and parish all analyses were adjusted for five classes of age, and instead of parish, population density. Parish was not used as the number of subjects in each stratum would have been too small for 
Table 2 Relative risk (95\% CI) of glioma, by sex, stratified for age and parish density, associated with industry (classified according to ISIC)

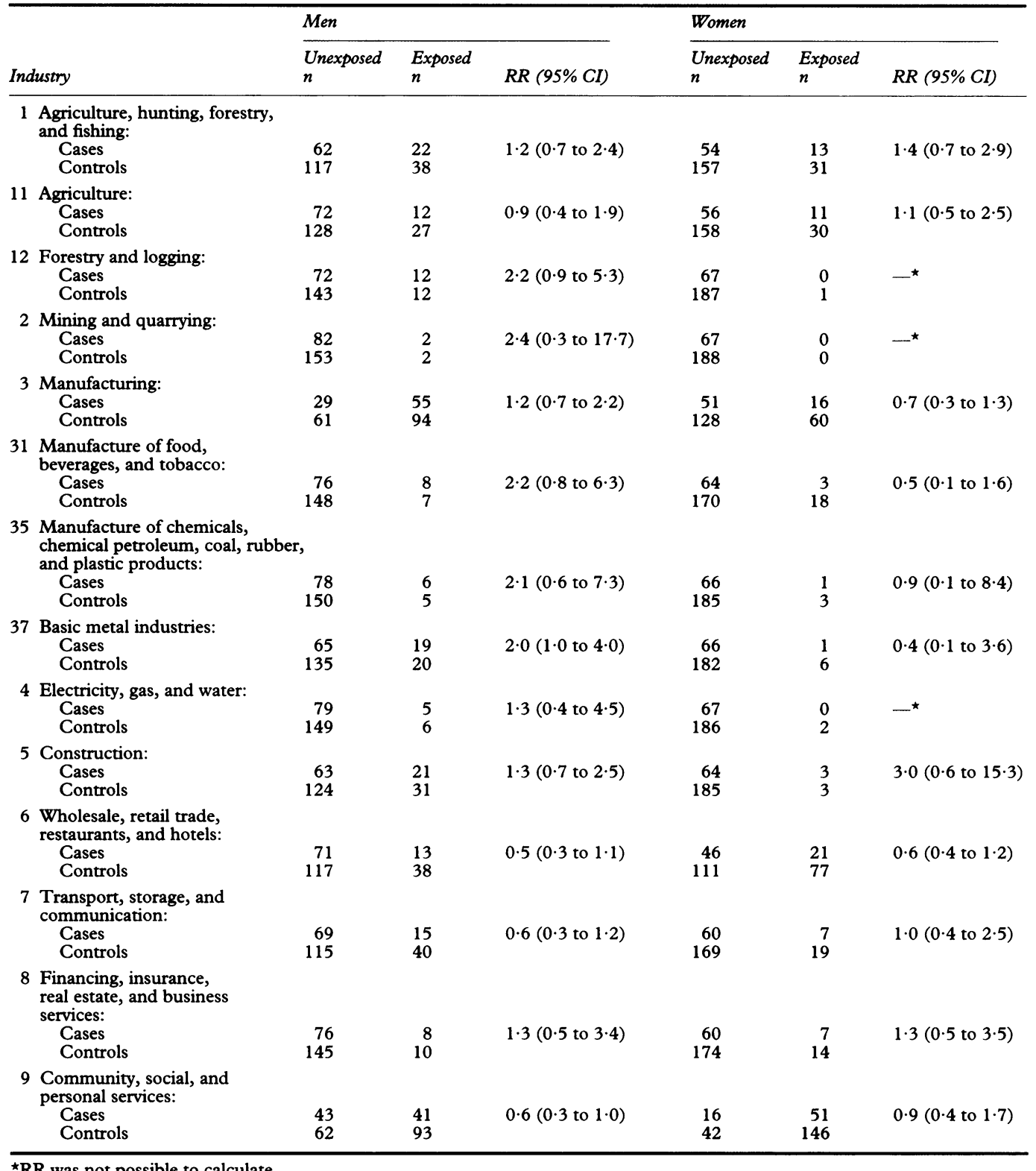

unconditional analyses. Conditional as well as unconditional analyses were performed but the results were similar. Unconditional analyses were then used because they allowed for the use of all controls which increased the precision of the estimates. Social class was also included in the models as a potential confounder. Duration in specific occupations was divided in two categories; $<10$ years and $\geqslant 10$ years. Analyses were also performed where duration of exposure in relation to diagnosis was considered. Time windows $0-10$ and 11-20 years before diagnosis or interview were used. Analyses were performed with and without proxies, and as the RR did not differ, the analyses with proxies included are presented here.

\section{Results}

Adjustment for social class had virtually no influence on the RR estimates and was therefore not included in the results presented.

The risk of glioma was evaluated by ISIC industry code. They are reported for all major groups (1 digit ). Subcategories (2 digits) were also analysed when there were at least five exposed cases in one of the sexes. They are reported if the $R R$ was at least $2 \cdot 0$. For the 1 digit group agriculture, hunting, forestry, and fishing, the RR for men was $1.2(95 \% \mathrm{CI}$ $0 \cdot 7-2 \cdot 4)$ and for women $1.4 \quad(95 \%$ CI $0 \cdot 7-2 \cdot 9)$. For the subcategory of agriculture, the RR was $0.9(95 \%$ CI $0.4-1.9)$ and for the subcategory of forestry and logging the RR was $2 \cdot 2(95 \%$ CI $0 \cdot 9-5 \cdot 3)$ for men. For people employed in the subcategory basic metal industries the $R R$ was 2.0 (95\% CI $1 \cdot 0-4 \cdot 0$ ) (table 2). For women no subcategory fulfilled the criteria to be reported. Dividing the employment according to duration did not show any further information.

In men, none of the major groups (1 digit) of job titles or subcategories ( 2 digits) had an $R R>2$ with more than five exposed cases (table 3).

All results from the main groups of self reported exposures are presented (table 4). 
Table 3 Relative risk (95\% CI) of glioma, by sex, stratified for age and parish density, associated with job title (classified according to ISCO)

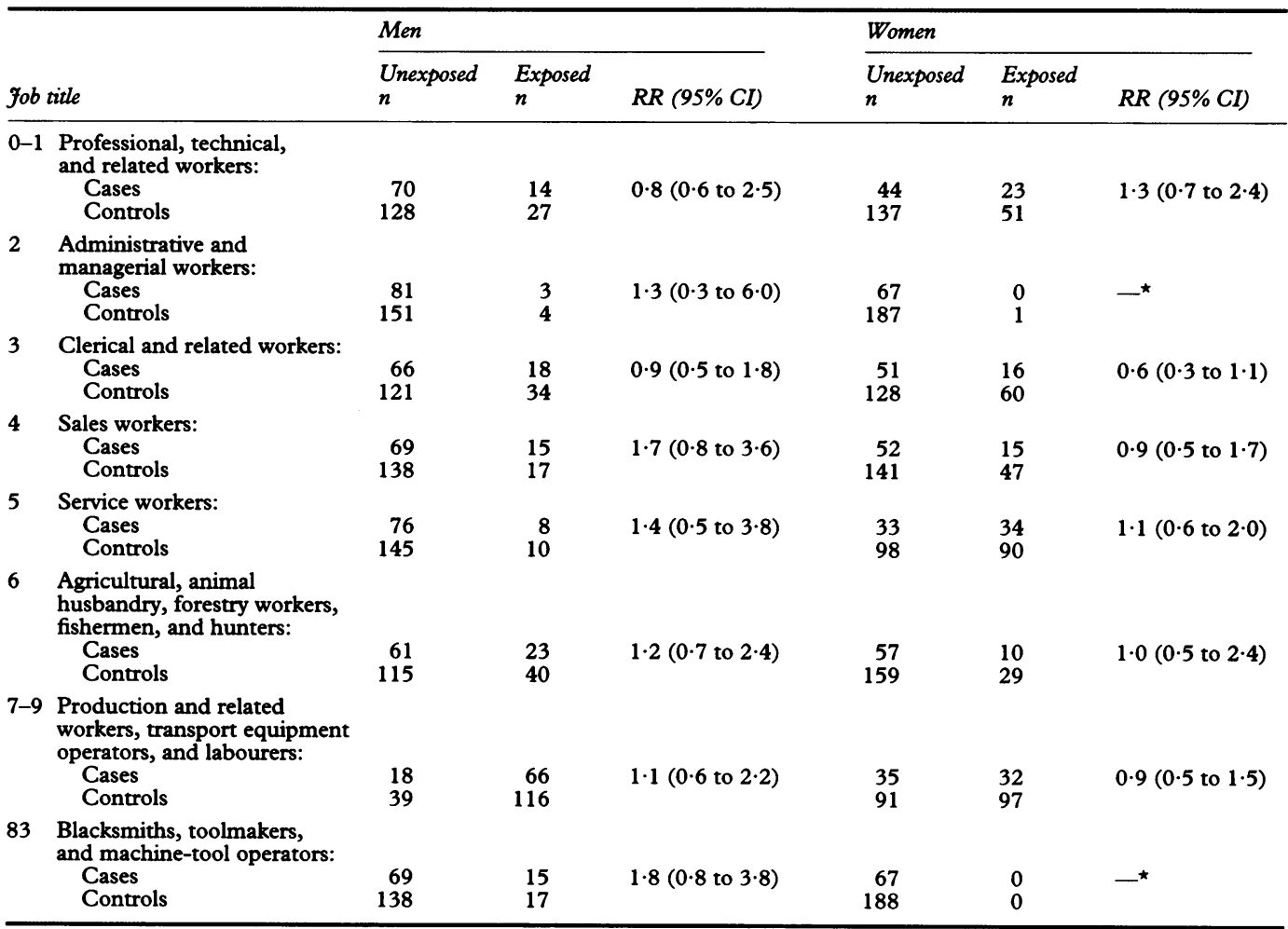

${ }^{\star} R R$ was not possible to calculate.

Table 4 Relative risk (95\% CI) of glioma, by sex, stratified for age and parish density, associated with self estimated exposures

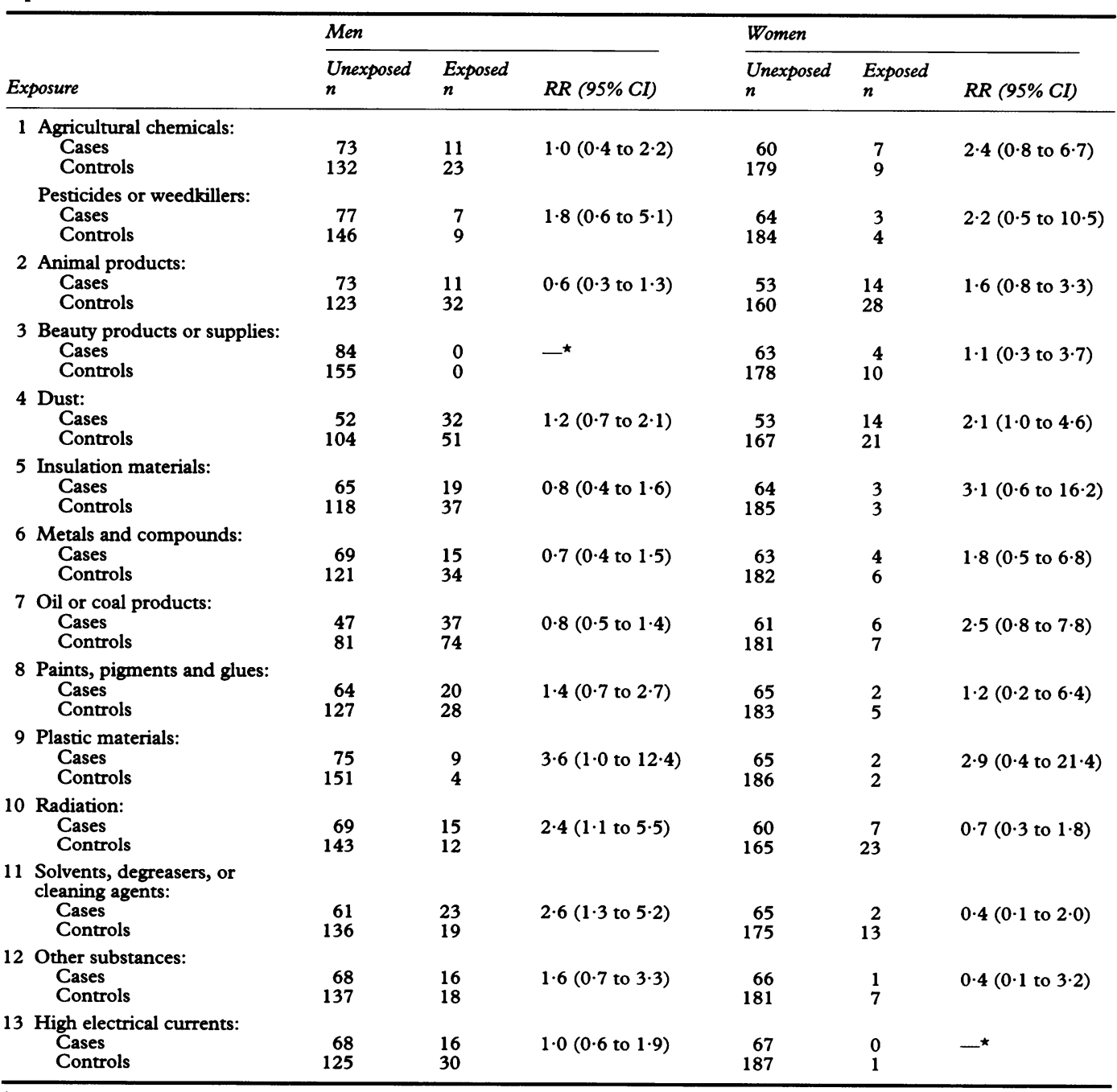

${ }^{\star} R R$ was not possible to calculate. 
Table 5 Classification according to self reported exposures and assessment by occupational hygienist ( $\mathrm{K}$ coefficient $(95 \% \mathrm{CI})$ )

\begin{tabular}{|c|c|c|c|c|}
\hline \multirow[b]{3}{*}{ Self estimated exposure } & \multicolumn{4}{|c|}{ Occupational hygienist } \\
\hline & \multicolumn{2}{|l|}{ Cases } & \multicolumn{2}{|l|}{ Controls } \\
\hline & Unexposed & Exposed & Unexposed & Exposed \\
\hline \multicolumn{5}{|l|}{ Pesticides: } \\
\hline Unexposed & 141 & $\begin{array}{l}0 \\
8\end{array}$ & 330 & 0 \\
\hline Exposed & \multirow{2}{*}{\multicolumn{2}{|c|}{$\begin{array}{c}0.88 \\
(0.72 \text { to } 1.04)\end{array}$}} & \multirow{2}{*}{\multicolumn{2}{|c|}{$\begin{array}{c}0.46 \\
(0.16 \text { to } 0.76)\end{array}$}} \\
\hline$(95 \% \mathrm{CI})$ & & & & \\
\hline \multicolumn{5}{|l|}{$\begin{array}{l}\text { Oil or coal products: } \\
\text { Unexposed }\end{array}$} \\
\hline Exposed & $\begin{array}{r}95 \\
5\end{array}$ & $\begin{array}{l}13 \\
38\end{array}$ & $\begin{array}{r}243 \\
14\end{array}$ & $\begin{array}{l}19 \\
67\end{array}$ \\
\hline$\underset{(95 \% \mathrm{CI})}{\kappa}$ & \multicolumn{2}{|c|}{$\begin{array}{c}0.72 \\
(0.60 \text { to } 0.84)\end{array}$} & \multicolumn{2}{|c|}{$\begin{array}{c}0.74 \\
(0.66 \text { to } 0.82)\end{array}$} \\
\hline \multicolumn{5}{|l|}{$\begin{array}{l}\text { Paints, pigments, } \\
\text { and glues: }\end{array}$} \\
\hline Unexposed & 129 & 0 & 308 & 2 \\
\hline Exposed & 12 & 10 & 20 & 13 \\
\hline$\underset{(95 \%}{K} \mathrm{CI})$ & \multicolumn{2}{|c|}{$\begin{array}{c}0.59 \\
(0.38 \text { to } 0.80)\end{array}$} & \multicolumn{2}{|c|}{$\begin{array}{c}0.51 \\
(0.33 \text { to } 0.69)\end{array}$} \\
\hline \multicolumn{5}{|l|}{ Plastic materials: } \\
\hline Unexposed & 140 & 0 & 337 & 0 \\
\hline Exposed & & 5 & 2 & 4 \\
\hline $\begin{array}{l}K \\
(95 \% \mathrm{CI})\end{array}$ & \multicolumn{2}{|c|}{$\begin{array}{c}0.61 \\
(0.32 \text { to } 0.89)\end{array}$} & \multicolumn{2}{|c|}{$\begin{array}{c}0.80 \\
(0.52 \text { to } 1.07)\end{array}$} \\
\hline \multicolumn{5}{|l|}{ Radiation: } \\
\hline Unexposed & 127 & 2 & 298 & 10 \\
\hline Exposed & 2 & 20 & 5 & 30 \\
\hline $\begin{array}{l}\kappa \\
(95 \% \mathrm{CI})\end{array}$ & \multicolumn{2}{|c|}{$\begin{array}{c}0.89 \\
(0.79 \text { to } 1.00)\end{array}$} & \multicolumn{2}{|c|}{$\begin{array}{c}0.78 \\
(0.67 \text { to } 0.88)\end{array}$} \\
\hline \multicolumn{5}{|l|}{$\begin{array}{l}\text { Solvents, degreasers, } \\
\text { or cleaning agents: }\end{array}$} \\
\hline $\begin{array}{l}\text { Unexposed } \\
\text { Exposed }\end{array}$ & 125 & 1 & 298 & 13 \\
\hline Exposed & 10 & 15 & 12 & 20 \\
\hline $\begin{array}{l}\kappa \\
(95 \% \mathrm{CI})\end{array}$ & $\begin{array}{r}0.6 \\
(0.52 \text { to }\end{array}$ & & $\begin{array}{l}0.58 \\
(0.43 \text { to }\end{array}$ & \\
\hline
\end{tabular}

For farmers who reported use of pesticides the RR was 1.3 (95\% CI 0.4-4.2), (data not presented). Pesticide use in any occupation resulted in an RR of 1.8 (95\% CI $0.6-5 \cdot 1)$, where $82 \%$ of the users were farmers and $18 \%$ were working in forestry. For women the corresponding $R R$ was $2 \cdot 2(95 \% \mathrm{CI} 0 \cdot 5-10 \cdot 5)$.

Nine cases and four controls among men who reported exposure to plastic materials had an RR of 3.6 (95\% CI 1.0-12.4). For women this RR was 2.9 (95\% CI $0.4-21.4$ ), but there were only two cases and two controls. Use of solvent produced an $\mathrm{RR}$ of $2.6(95 \% \mathrm{CI}$ 1.3-5.2) among men. When analysing data according to different subgroups of solvents benzene produced an RR of $5.5(95 \% \mathrm{CI}$ 1.4-21.3), toluene $R R \quad 3.4 \quad(95 \% \quad \mathrm{CI}$; 0.6-19.3), trichloroethylene RR 2.4 (95\% CI; $0.9-6.4)$, and xylene RR 3.3 (95\% CI; $0 \cdot 6-18 \cdot 6$ ) (data not shown).
Three cases and one control reported exposure to ionising radiation. All had been working in dental or medical care (data not shown).

The self reported exposures were compared with those assessed by the occupational hygienist to compare the degree of agreement among cases and controls. The $\kappa$ coefficients were calculated for the main groups and were between 0.46 and 0.88 and the largest difference between cases and controls was for pesticide use (table 5). It did not change if proxies were excluded from the analyses. When the occupational hygienist excluded those not adequately confirmed, the risk estimates increased to $4.9(95 \% \mathrm{CI} 1 \cdot 2-20 \cdot 6)$ for men and to 6.8 $(95 \%$ CI $4 \cdot 2-11 \cdot 2)$ for women. However, these analyses are based on small numbers. There was no information about specific pesticides (data not shown).

When analysing the data according to social class, the lowest class (III) was treated as a reference. For class I the RR was estimated at $1 \cdot 7$ $(95 \% \mathrm{CI} 0.7-4 \cdot 2)$ for men and $0.7(95 \% \mathrm{CI}$ $0 \cdot 2-2 \cdot 7)$ for women. For class II the RR was $0.8(95 \%$ CI $0.5-1.4)$ for men and $0.8(95 \%$ CI 0.4-1.4) for women (table 6). A tendency to an increased risk was found for women who had been to University (table 7 ).

\section{Discussion}

In this study we found some support for an increased risk of glioma for those exposed to solvents, pesticides, and plastic materials, and for those working in the forestry or basic metal industries. However, based on small numbers these results should be interpreted cautiously.

The fact that this is a population based study means that all cases in the study base are identified and that a valid source for controls exists which reduces risk of bias. The nonresponse rate was higher among those with the most malignant tumours. If there is an association between exposure and grade of malignancy this could influence the results, but there is no support for such an association in previous findings. There is a possibility that stratification on population density does not fully account for the matching on parish, but this would underestimate the RR rather than give rise to spurious findings. There were no differences in population density between

Table 6 Relative risk (95\% CI) of glioma, in men and women, stratified for age and parish density by social class

\begin{tabular}{|c|c|c|c|c|c|c|}
\hline \multirow[b]{2}{*}{ Social groups } & \multicolumn{3}{|c|}{$\operatorname{Men}(n)$} & \multicolumn{3}{|c|}{ Women (n) } \\
\hline & $I I I$ & $I I$ & $I$ & III & II & $I$ \\
\hline $\begin{array}{l}\text { Cases } \\
\text { Controls } \\
\text { RR } \\
(95 \% \text { CI })\end{array}$ & $\begin{array}{r}45 \\
79 \\
1\end{array}$ & $\begin{array}{l}28 \\
65 \\
0.8 \\
(0.5 \text { to } 1.4)\end{array}$ & $\begin{array}{l}11 \\
11 \\
1 \cdot 7 \\
(0 \cdot 7 \text { to } 4 \cdot 2)\end{array}$ & $\begin{array}{r}34 \\
86 \\
1\end{array}$ & $\begin{array}{l}28 \\
90 \\
0.8 \\
(0.4 \text { to } 1.4)\end{array}$ & $\begin{array}{c}3 \\
11 \\
0 \cdot 7 \\
(0 \cdot 2 \text { to } 2 \cdot 7)\end{array}$ \\
\hline
\end{tabular}

Table 7 Relative risk (95\% CI) of glioma, in men and women, stratified for age and parish density by education

\begin{tabular}{|c|c|c|c|c|c|c|}
\hline \multirow[b]{2}{*}{ Years in school } & \multicolumn{3}{|l|}{ Men } & \multicolumn{3}{|c|}{ Women } \\
\hline & $<8$ & $\geqslant 8$ & University & $<8$ & $\geqslant 8$ & University \\
\hline $\begin{array}{l}\text { Cases } \\
\text { Controls } \\
\text { RR } \\
(95 \% \text { CI })\end{array}$ & $\begin{array}{r}29 \\
68 \\
1\end{array}$ & $\begin{array}{l}55 \\
87 \\
1 \cdot 2 \\
(0 \cdot 6-2 \cdot 2)\end{array}$ & $\begin{array}{l}11 \\
13 \\
1 \cdot 2 \\
(0 \cdot 7-2 \cdot 4)\end{array}$ & $\begin{array}{r}26 \\
88 \\
1\end{array}$ & $\begin{array}{l}41 \\
99 \\
1 \cdot 3 \\
(0 \cdot 4-3 \cdot 9)\end{array}$ & $\begin{array}{l}9 \\
19 \\
2 \cdot 0 \\
(0 \cdot 6-6 \cdot 2)\end{array}$ \\
\hline
\end{tabular}


cases and controls, nor between the respondents and non-respondents.

In a case-control study we are always concerned about recall bias, and there have been few attempts to validate work histories. For job titles this is not considered a major problem, ${ }^{31-33}$ but for exposure the agreement is found to be lower. ${ }^{33}$ In two studies no difference in agreement was found between cases and controls. ${ }^{31}{ }^{33}$ In this study the $\kappa$ coefficients for the classification by the two methods were between 0.46 and 0.88 and were almost the same for cases and controls. However, differential recall bias could explain the reported relation for specific substances, but, there is no reason to think that it should occur only for some specific and not for all exposures.

The fact that we replaced controls who refused to participate with new controls may not counter any bias caused by non-response. The results did not change when the replaced controls were included, we retained them in the analyses to increase numbers and, thus, statistical precision.

For those who had been working in the basic metal industries including iron, steel, and non-ferrous industries we found an increased risk and this is supported from a large case-control study among men based on death certificates where an OR of $2 \cdot 1(95 \% \mathrm{CI}$ $1 \cdot 2$ to $3 \cdot 6$ ) was found for all precision metal workers. ${ }^{34}$

Farmers are at lower risk for most major diseases than the general population. However, pesticides and other agricultural chemicals have been linked to an increased risk of brain tumours. We found no excess in risk when analysing data for farmers as an occupation in this study, but an RR of 1.8 was found for those who reported pesticide use.

In Sweden, a cohort of licensed pesticide applicators in agriculture was followed up between 1965 and 1976, and a slight but not significant increase in risk ( $R R \quad 1 \cdot 3)$ for tumours of the nervous system was found. ${ }^{35}$ Two studies conducted in Italy showed an increased risk among farmers and the authors attributed the excess to pesticides. ${ }^{3637}$ An increased risk was also found in another Italian cohort; however, this was based on small numbers. ${ }^{38}$

An increased risk for men who had been working in forestry and logging was found in this study, which is supported by a cancer registry based case-control study in New Zealand, ${ }^{39}$ and in the study of mortality from brain tumours by Demers et al. ${ }^{21}$

We found an increased risk for those who reported use of solvents, mostly in industrial occupations. The solvents associated with increased risks were substances such as benzene, trichloroethylene, and xylene. The results from previous studies suggest that organic solvents may be carcinogenic, although the results were based on small numbers. ${ }^{61415}$ In a case-control study in the United States, chlorinated aliphatic hydrocarbons were evaluated as potential risk factors for astrocytic brain tumours. A job exposure matrix was applied and provided estimates of probability and intensity of exposure. Risk increased significantly with probability of exposure to organic solvents and to methylene chloride. ${ }^{16}$ In Finland an increase in incidence of cancer of the nervous system was found for those exposed to $1,1,1$ - trichloroethane. ${ }^{17}$

An increased risk for both men and women was found in this study for those with self reported exposure to plastic material, including polyethylene, polystyrene, polyurethane, and polyvinyl chloride. In Los Angeles an increased risk of brain tumours was found for those who had been working with plastic materials, ${ }^{5}$ and in a large European multicentre cohort study among vinyl chloride workers there was an indication of an effect, significant at $\geqslant 30$ years since first exposure on the basis of four observed deaths (SMR $4 \cdot 1,95 \% \mathrm{CI}$ $1 \cdot 1$ to $10 \cdot 4) .^{40}$

We found a tendency to an increased risk for men in the highest social class. In Sweden it is not reasonable to assume that there are substantial differences in medical care, which has been put forward as an explanation in some other countries.

We thank Ms B Wellander, Ms B Schramm, Ms AC Wistedt, Ms G Johnson, Mr A Bjurman, Ms M Lindewall, and The Regional Cancer Registry in Uppsala for fruitful collaboration. This work was supported by the Swedish Cancer Society and The Work Environment Fund.

1 Wrench M, Bondy ML, Wiencke J, Yost M. Environmental risk factors for primary malignant brain tumors: a review. fournal of Neuorooncology 1993;17:47-64

2 Bondy ML, Lustbader ED, Buffler PA, Schull WJ, Hardy RJ, Strong LC. Genetic epidemiology of childhood brain tumors. Genet Epidemiol 1991;8:253-67.

3 Bernstein M, Laperriere N. Radiation-induced tumours of the nervous system. In: Gutin PH, Leibel SA, Sheline GE. eds. Radiation injury to the nervous system 1991: 455-72.

4 Burch JD, Craib KJP, Choi BCK, Miller AB, Risch HA, Howe GR. An exploratory case-control study of brain
tumors in adults. $\mathcal{F}$ Natl Cancer Inst 1987;78:601-9.

5 Preston-Martin S, Mack W, Hendersson BE. Risk factors for gliomas and meningiomas in males in Los Angeles County. Cancer Res 1989;49:6137-43.

6 Thomas TL, Waxweiler RJ. Brain tumours and occupational risk factors. Scand $\varsubsetneqq$ Work Environ Health 1986;12: $1-15$

7 Waxweiler RJ, Stringer W, Wagoner JK, Jones J. Neoplastic risk among workers exposed to vinyl chloride. Ann NY risk among workers exp.
Acad Sci 1976;271:40-8.

8 Cooper WC. Epidemiologic study of vinyl chloride workers: mortality through December 31, 1972. Environ ers: mortality through Decem

9 Beaumont J. Breslow NE. Power considerations in epidemiologic studies of vinyl chloride workers. $\mathrm{Am} \mathcal{F}$ Epidemiol 1981;114:725-34.

10 Blair A, Zahm SH. Cancer among farmers. Occup Med 1991;6:335-54.

11 Thomas TL, Stolley PD, Stemhagen A, Fontham ETH, Bleecker ML, Stewart PA, et al. Brain tumor mortality risk among men with electrical and electronic jobs. A case-control study. $\mathcal{F}$ Natl Cancer Inst 1987;79:233-8.

12 Floderus B, Persson T, Stenlund C, Wennberg A, Öst A, Knave B. Occupational exposure to electromagnetic fields in relation to leukemia and brain tumours a casecontrol study in Sweden. Cancer Causes Control 1993;4: control st

13 Savitz DA, Loomis DP. Magnetic field exposure in relation to leukemia and brain cancer mortality among electric utility workers. Am $\mathcal{F}$ Epidemiol 1995;141:123-34.

14 Cordier S, Poisson M, Gerin M, Varin J, Conso F, Hemon $\mathrm{D}$. Gliomas and exposure to wood preservatives. $\mathrm{Br} \mathcal{F}$ Ind Med 1988;45:705-9.

15 Park RM, Silverstein MA, Green MA, Mirer FE. Brain cancer mortality at a manufacturer of aerospace electromechanical systems. Am $₹$ Ind Med 1990;17:537-52.

16 Heineman EF, Cocco P, Gomez MR, Dosemeci M, Stewart PA, Hayes RB, et al. Occupational exposure to Stewart $\mathrm{PA}$, Hayes $\mathrm{RB}$, et al. Occupational exposure to
chlorinated aliphatic hydrocarbons and risk of astrocytic chlorinated aliphatic hydrocarbons and risk

17 Anttila A, Pukkala E, Sallmén M, Hernberg S, Hemminki K. Cancer incidence among Finnish workers exposed to $\mathrm{K}$. Cancer incidence among Finnish workers exposed to
halogenated hydrocarbons. F Occup Environ Med 1995; 37:797-806.

18 Boyle P, Maisonneuve P, Saracci R, Muir CS. Is the 
increased incidence of primary malignant brain tumors in the elderly real? $\mathcal{N}$ Natl Cancer Inst 1990;82:1594-6.

19 Modan B, Wagener DK, Feldman J, Rosenberg HM, Feinleib M. Increased mortality from brain tumors: a combined outcome of diagnostic technology and change of attitude toward the elderly. Am $\mathcal{F}$ Epidemiol 1992; 135:1349-57.

20 Desmeules $M$, Mikkelsen $T$, Yang $M$. Increasing incidence of primary malignant brain tumors: influence of diagnostic methods. F Natl Cancer Inst 1992;42:442-5.

21 Demers PA, Vaughan TL, Schommer RR. Occupation, socioeconomic status, and brain tumour mortality: a
death certificate-based case-control study. $\mathcal{O}$ Occup Med death certificate-bas

22 Preston-Martin S. Descriptive epidemiology of primary tumors of the brain, cranial nerves and cranial meninges in Los Angeles County. Neuroepidemiology 1989;8:283-95.

23 World Health Organization. International classification of diseases for oncology. Geneva: WHO, 1976.

24 Kernohan JW, Mayborn RF, Svien HJ, Adson AW. A simplified classification of the gliomas. Proc Staff Meet Mayo Clin 1949;24:71-5.

25 Indexes to the international standard industrial classification of all economic activities. New York: Publishing Division, all economic activities.

26 International standard classification of occupations. Geneva: International Labour Organisation, 1968.

27 AFS Arbetarskyddsstyrelsens författningssamling. Hygieniska gränsvärden AFS 1993:9. Stockholm, Sweden: Svenskt Tryck, 1993.

28 Taube AAS. To judge the judges-kappa, roc or what? Uppsala, Sweden: Uppsala University Research Report, 1994:3.

29 Statistics Sweden. Swedish socioeconomic classification. Stockholm: Statistics Sweden, 4:1984.

30 Breslow NE, Day NE. Statistical methods in cancer research, vol 1-the analysis of case-control studies. Lyon: IARC, 1980. (IARC Sci Publ No 32.)

31 Baumgarten M, Siemiatycki J, Gibbs GW. Validity of work histories obtained by interview for epidemiologic purposes. Am $\mathcal{F}$ Epidemiol 1983;118:583-91.

32 Stewart WF, Tonascia JA, Matanoski GM. f Occup Med 1987;29:795-800.

33 Bond GG, Bodner KM, Sobel W, Shellenberger RJ, Flores GH. Validation of work histories obtained from interviews. Am $\mathcal{\Im}$ Epidemiol 1988;128:343-51.

34 Thomas TL, Fontham ETH, Norman SA, Stemhagen A, Hoover RN. Occupational risk factors for brain tumors. Scand 7 Work Environ Health 1986;12:121-7.

35 Wiklund K, Dich J, Holm L-E, Eklund G. Risk of cancer in pesticide applicators in Swedish agriculture. Br $\mathcal{F}$ Ind Med 1989;46:809-14.

36 Musicco M, Filippini G, Bordo BM, Melloto A, Morello $G$, Berrino F. Gliomas and occupational exposure to carcinogens: case-control study. Am $\mathcal{F}$ Epidemiol 1982;116: 782-90.

37 Musicco M, Sant M, Molinari S, Filippini G, Gatta G, Berrino F. A case-control study of brain gliomas and occupational exposure to chemical carcinogens: the risk to farmers. Am $\mathfrak{f}$ Epidemiol 1988;128:778-85.

38 Figá-Talamanca I, Mearelli I, Valente P, Bascherini S. Cancer mortality in a cohort of rural licensed pesticide users in the province of Rome. Int 7 Epidemiol 1993;22: users in

39 Reif JS, Pearce N, Fraser J. Occupational risks for brain cancer: a New Zealand cancer registry-based study. $\mathcal{f}$ Occup Med 1989;31:863-7.

40 Simonato L, Abbe KA, Andersen A, Belli S, Comba P, Engholm G, et al. A collaborative study of cancer incidence and mortality among vinyl chloride workers. Scand f Work Environ Health 1991;17:159-69.

\section{Vancouver style}

All manuscripts submitted to Occup Environ Med should conform to the uniform requirements for manuscripts submitted to biomedical journals (known as the Vancouver style.)

Occup Environ Med, together with many other international biomedical journals, has agreed to accept articles prepared in accordance with the Vancouver style. The style (described in full in the BMF, 24 February $1979, p$ 532) is intended to standardise requirements for authors.

References should be numbered consecutively in the order in which they are first mentioned in the text by Arabic numerals above the line on each occasion the reference is cited (Manson ${ }^{1}$ confirmed other reports $^{2-5} \ldots$.). In future references to papers submitted to Occup Environ Med should include: the names of all authors if there are seven or less or, if there are more, the first six followed by et al; the title of journal articles or book chapters; the titles of journals abbreviated according to the style of Index Medicus; and the first and final page numbers of the article or chapter. Titles not in Index Medicus should be given in full.

Examples of common forms of references are:

1 International Steering Committee of Medical Editors, Uniform requirements for manuscripts submitted to biomedical journals. Br Med f 1979;1:532-5.

2 Soter NA, Wasserman SI, Austen KF. Cold urticaria release into the circulation of histamine and eosinophil chemotactic factor of anaphylaxis during cold challenge. N Engl f Med 1976;294:687-90.

3 Weinstein L Swartz MN. Pathogenic properties of invading micro-organisms. In: Sodeman WA Jr, Sodeman WA of disease. Philadelphia: W B Saunders, 1974:457-72. 